\title{
SHIP PLANNED MAINTENANCE SYSTEM DATA ANALYSIS
}

\author{
Tatjana Stanivuk ${ }^{1}$, Ladislav Stazić ${ }^{2}$, Frane Vidović ${ }^{3}$, Ante Čobanov ${ }^{4}$ \\ 1,2,4 University of Split, Faculty of Maritime Studies, Split, Croatia \\ ${ }^{3}$ Self-employed, Split, Croatia
}

Received 15 May 2020; accepted 20 July 2020

\begin{abstract}
This paper presents available results of an ongoing research into the computerized ship Planned Maintenance Systems (PMS) and their databases. Evaluation of Computerized Planned Maintenance Databases is, at the moment, a process which requires highly skilled personnel, familiar with the Company structure and policies, familiar with the engineering practices and above all, familiar with the Computer program which is used for the PMS. The ongoing research has the purpose to perform evaluation of the Computerized PMS using normally skilled person, with medium level of skills, without using specially developed tools for the evaluation. During the first part of the research, a new method of evaluation was tried, and the obtained results were compared with the evaluation of the expert which was previously conducted on the same database.
\end{abstract}

Keywords: Planned Maintenance System, database, evaluation, data quality.

\section{Introduction}

Computerized PMS (Planned Maintenance Systems) for ships are widely used all over the world for more than thirty years (Knežević et al., 2019). PMS are governed by several rules and regulations, where one of the most important is ISM code, Chapter 10 (International Safety Management Code, 2015). "Despite relatively long period of their application, database quality, configuration and content are still open to various interpretations" (Stazić et al., 2017).

Maintenance is of the utmost importance in shipping industry, it affects the safety and reliability of the ship and therefore it needs to be constantly monitored and improved. Organization and implementation of the PMS is a mode to monitor and improve company maintenance procedures.
PMS system database is based on three main sources (Stazić et al., 2019):

- Manufacturer data;

- Various rules and regulations;

- Company Safety Management System (SMS), representing company experience in management and maintenance.

PMS database consists of the multitude of the information; there should be information about all spares, spare parts details, dimensions, manufacturer and vendor contact details, recommended maintenance and various other information which are coming predominantly from the manufacturer data. Evaluation of the quality of the data in the PMS database has been addressed during previous researches. The quality of the PMS database can be determined using the questionnaire (Stazić

${ }^{2}$ Corresponding author: 1stazic@pfst.hr 
et al., 2017) in a process which requires advanced knowledge of the engineering, knowledge of the Company structure and policies and very good knowledge of the used PMS system. Process itself is also time consuming, it takes several (two, three, sometimes four) hours per database. Those requirements Sare complicating the evaluation of the PMS systems, requiring highly skilled person for the task, creating the evaluation process more expensive for the shipping companies.

The idea of this research is to try to develop a new methodology for the evaluation of the PMS database which will be simple enough to be used by ordinary person (not requiring an expert for the task) and which will be performed in a fraction of time needed for the previous evaluation.

\section{The Concept of the New Methodology}

In order to fulfill first condition, set for the new methodology, a Marine Engineering student was chosen for the evaluation of the PMS database. The student has no knowledge of the Company policy structure and policies, he has theoretical knowledge of the engineering practices and he is not familiar with the Computer program used for the PMS. In short, student capabilities can be described as "normal" and in every shipping company there is certain number of similarly qualified persons.

Creating the methodology aims to establish the method which everybody can perform. The idea for the new methodology is to determine whether is possible to establish the ratio between quantity of the data and the quality of the data and whether the quantity of the information in the computer database can indicate the database quality and the quality of the ship maintenance. In order to minimize the duration of the evaluation (second task set for the methodology) whole PMS database should not be analyzed. Instead, limited sample will be analyzed in order to determine the quality (Kolossa and Kopp, 2018; Jung, 2017) of the overall PMS database by measuring the quantity of the information linked. A sample of several pumps was analyzed in the computer database of one shipping company. Obtained results give the information about the number of information linked on individual devices, sorted according to their purpose. The conclusion of this part of the research accurately determines the amount of information associated with the pumps within the PMS database as well as indicates to the answer on the main question.

Byproduct of the research will answer the question on the quantity of the information is inserted into the PMS database, an information which will become representative after analyzing large number of databases.

According to the paper author knowledge, until now nobody attempted to quantify the quantity of the data in the database and to find out if the quantity of the data has any correlation to the maintenance and/or organization of the company.

\subsection{Non-disclosure Condition}

As shipping company allowed access to their database strictly under no disclosure condition, all details leading to identification of the ship and/or the company are removed from the article. Some of the classified data will also be omitted from this paper. 


\section{Research and Results}

Research is performed in the real company PMS database. There are eighty-five pumps in the database; some of them are visible on the Figure 1.

Equipment details are visible on the right side of the Figure 1; following details are taken from manufacturers manual and Class Society data:

- Maker name;

- Product type;

- Serial number (deleted from the figure due to no disclosure condition);

- Drawing number;

- Survey list code (deleted from the figure due to no disclosure condition).

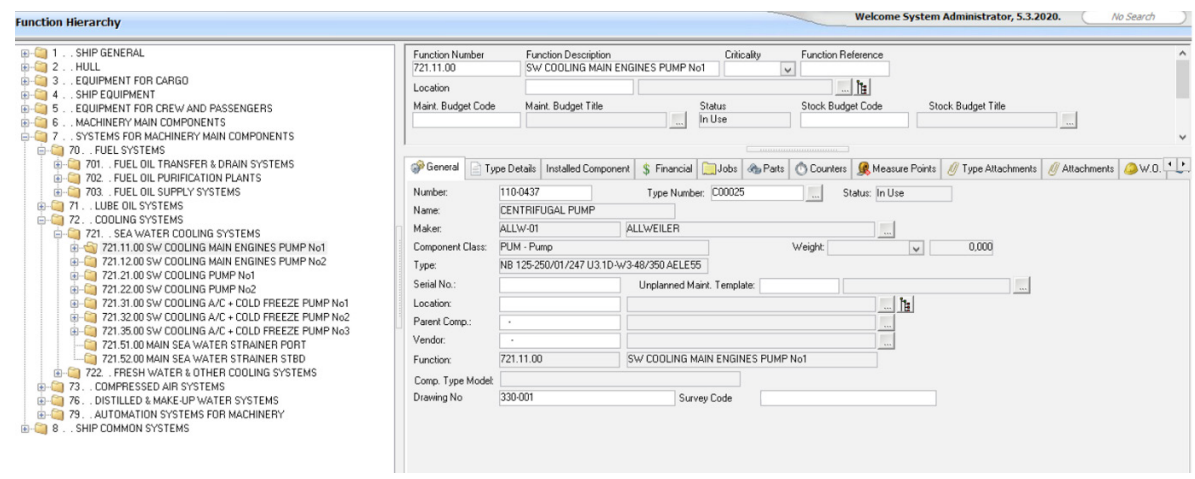

Fig. 1.

A Screenshot from PMS Database

Sample of pumps has been created randomly; quantification of the all information linked for chosen pumps is presented in Table 1 .

Table 1

Analysis Results

\begin{tabular}{|c|c|c|c|c|c|}
\hline Equipment Name & $\begin{array}{c}\text { Equipment } \\
\text { Details No }\end{array}$ & $\begin{array}{c}\text { Spares } \\
\text { Number No }\end{array}$ & $\begin{array}{c}\text { Details no Per } \\
\text { Spare Part }\end{array}$ & $\begin{array}{c}\text { Purchase Data } \\
\text { No Per Spare }\end{array}$ & $\begin{array}{c}\text { Work Data } \\
\text { No }\end{array}$ \\
\hline SW Cooling Pump & 8 & 51 & 4.02 & 1 & 3 \\
\hline FO Transfer Pump & 7 & 28 & 4 & 1 & 3 \\
\hline Firefighting Pump & 7 & 0 & 0 & 1 & 3 \\
\hline Bilge/Ballast Pump & 8 & 51 & 4.04 & 1 & 3 \\
\hline Liquid Mud/Brine Pump & 1 & 0 & 0 & 1 & 1 \\
\hline Emergency FF Pump & 7 & 51 & 4.04 & 1 & 2 \\
\hline Bilge Piston Pump & 5 & 64 & 4 & 3 & 2 \\
\hline Average & 6.14 & 35 & 2.87 & 1.29 & 2.42 \\
\hline
\end{tabular}




\section{Discussion}

Analyzing Table 1 following can be concluded:

- $14 \%$ of the analyzed components do not have well defined equipment details;

- Overall number of equipment details is in order;

- 28.6 percent of the analyzed pumps do not have spares attached;

- All pumps with spare parts have all required spare part details linked;

- Purchase data is very limited, there is data only about manufacturer (original vendor) data;

- For $14 \%$ of the analyzed components maintenance plan can be improved.

Therefore, final opinion of the evaluator (student) about this DB quality is presented below.

DB has all chosen components; majority of components have linked equipment details. Spare parts are linked to majority of components; maintenance plan is in order on the majority of sample. DB must be improved in the area of linked spare parts; 28.6 percent of the sample does not have spares attached. Another area for the improvement of the DB is on $14 \%$ of analyzed components where equipment details and maintenance plan can be improved.

Results of the previous evaluation (Stazić et al., 2017) by an expert on the same database (database no.5) produced following opinion:

Database on average is in order, overall grade is in order, and database does not require immediate action. There are some areas where action is required and recommended, i.e. some components are without spare parts and critical spares are not marked, maintenance plan on some components should be improved. There are some other minor remarks, among other is that some components do not have well defined equipment details.

Results of both methodologies are leading to the same conclusion, that $\mathrm{DB}$ overall is in order with some areas where it must be improved and some areas where it can (and does not have to) be improved. Detected improvement areas in both methodologies are the same, although evaluation by expert provided much more detailed results and detailed description of problems (deficiencies).

Although these results are encouraging and motivating, it can not be used to form any conclusion, "small sample should not lead to great conclusions" (Tversky and Kahneman, 1971).

\section{Conclusion}

A methodology for the evaluation of the quality of the Computerized Planned maintenance system database has been developed following two basic requirements set as necessary. First condition was simplicity of use and second was that duration of the evaluation is as short as possible, to be finished in minutes. Basic idea is to try to introduce the simplest methodology, counting the number of the proper information linked to the designated components and forming an opinion based on number counted. As database has large number of components, and it will take very long time to quantify components and information linked, it was obvious that 
only small sample of components should be checked. Therefore, several components, randomly chosen, were analyzed, information linked to them collected and sorted. Evaluation was performed by a student to check if the methodology is simple enough for the use by normally skilled person. An opinion on database quality is formed based on the collected data. Comparisons of student's opinion on the database are compared with the expert evaluation of the same database, performed two years ago. Results of both methodologies are leading to the same conclusion on the database quality and both evaluations recommended more or less similar steps for improvement of the database.

Although results of this part of the research gave results that are very promising, there are many more databases to be evaluated before any conclusion about this methodology can be formulated. Presently, the conclusion is that newly developed PMS database evaluation method gave similar results as the old methodology, but on only one database!

\section{Acknowledgements}

Part of the research for this article was performed using the equipment obtained through the Project named 'Functional integration of the University of Split, PMFST, PFST and KTF-ST through development of scientific and research infrastructure in three faculties building", contract number KK.01.1.1.02.0018.

\section{References}

International Safety Management Code. 2015. Revised ISM Code Effective as from 1 January 2015 Available from internet: <https://www.classnk.or.jp/hp/pdf/ activities/statutory/ism/ISM_Cd/ISM-Code-e.pdf $>$.

Jung, H. J. 2017. The Quantity Data Estimation for Software Quality Testing, Journal of the Korea Convergence Society 8(10): 37-43. https://doi.org/10.15207/ JKCS.2017.8.4.037.

Knežević, V.; Stazić, L.; Orović, J.; Mihanović, L. 2019. Use of PMS Continuous Improvement Scheme for Maintenance Adjustments in Shipping Industry. In Book od Proceedings - 8th International Maritime Science Conference (IMSC 2019) (Kotor CIP-National library of Montenegro), 415-420.

Kolossa, A.; Kopp, B. 2018. Data quality over data quantity in computational cognitive neuroscience, NeuroImage 172: 775-785. https://doi.org/10.1016/j. neuroimage.2018.01.

Stazić, L.; Komar, I.; Račić, N. 2017. Evaluation Methodology for Ship's Planned Maintenance System Database, Transactions on Maritime Science 6(2): 109-116.

Stazić, L.; Bratić, K.; Mihanović, V.; Matjašić, J. 2019. Maintenance process adjustment based on Computerized PMS data. In Book od Proceedings - 1st International Conference of Maritime Science \& Technology Naše More 2019, 547-553.

Tversky, A.; Kahneman, D. 1971. Belief in the law of small numbers, Psychological bulletin 76(2): 105-110. https://doi.org/10.1037/h0031322. 